\title{
MODULATION OF MENOPAUSAL HOT FLASHES BY AMBIENT TEMPERATURE
}

\author{
Fredi Kronenberg ${ }^{1 *}$ and Ruth M. BarNard ${ }^{2}$ \\ 'Department of Rehabilitation Medicine, College of Physicians \& Surgeons, Columbia University, New \\ York, NY 10032 and ${ }^{2}$ School of Nursing, University of Michigan, Ann Arbor, MI 48109, U.S.A.
}

(Received 13 May 1991; accepted 1 September 1991)

\begin{abstract}
The effect of ambient temperature on frequency, intensity and duration of hot flashes was studied in six women with hot flashes who were exposed to cool $\left(T_{\mathrm{a}}=19^{\circ} \mathrm{C}\right)$ and warm $\left(T_{\mathrm{a}}=31^{\circ} \mathrm{C}\right) T_{\mathrm{a}} \mathrm{s}$ for 8-h periods. Heart rate, skin resistance, core and skin temperatures, subjective hot flash intensity and duration were recorded.

2. In the cool $T_{\mathrm{a}}$ as compared with the warm $T_{\mathrm{a}}$, hot flashes were significantly less frequent $(3.0 \mathrm{HFs} / 8 \mathrm{~h}$ vs $12.2 \mathrm{HFs} / 8 \mathrm{~h}, P<0.001)$ and less intense $(2.0 \mathrm{vs} 5.6, P<0.007)$, and tended to be of shorter duration ( $2.1 \mathrm{~min}$ vs $5.5 \mathrm{~min}, P<0.054$ ).

3. The modulation of hot flashes by ambient temperature may be due to changes in central thermoregulatory thresholds, modification of thermoregulatory effectors, or alteration of the mechanism that initiates hot flashes.
\end{abstract}

Key Word Index: Menopause; hot flash; hot flush; thermoregulation; skin resistance; ambient temperature; human

\section{INTRODUCTION}

The relationship between menopausal hot flashes and a decline in ovarian function has been recognized for a century. Yet it is only in the past 15 years that the sensation of heat, by which a hot flash has been defined, was demonstrated to be accompanied by measurable changes in thermoregulatory variables such as sweating, skin temperature, heart rate, and core temperature. This characteristic sequence of events is consistent with the hypothesis that a hot flash is an integrated thermoregulatory response resulting from a transient lowering of the body's thermoregulatory set point (Tataryn et al, 1980). From a practical standpoint, these episodes result in a disturbance of night-time sleep as well as daily functioning. At present, one third of all women in the U.S. have reached menopausal age, and $75 \%$ of American women at menopause experience hot flashes (Kronenberg, 1990). Despite this ubiquitous problem, there is still an inadequate understanding of the mechanism of hot flashes.

Women report that their hot flashes seem "worse" (more frequent and intense) in the heat than in the cold. Studies that have examined the relationship between the frequency of hot flashes and environmental temperature have yielded mixed results. Coope et al. (1978) reported an increase in the mean daily number of hot flashes with increases in the daily minimum and maximum outdoor temperature for 25 subjects who recorded their hot flashes for 2 months.

*All correspondence should be addressed to: Fredi Kronenberg, Ph.D., Columbia University, College of Physicians \& Surgeons, Box 38,630 W. 168th St, New York, NY 10032, U.S.A. [Tel. (212) 305-2009; Fax. (212) 305-1493.]
Molnar (1981) also found a direct correlation between environmental temperature and the daily number of hot flashes for one subject who recorded her hot flashes for 100 days. In two other studies of factors associated with hot flashes, the investigators observed that there was no relationship between hot flash frequency and air temperature (Voda, 1981; Gannon et al., 1967). Inconsistencies in the reported relationships between hot flash frequency and environmental temperature are not surprising, considering that ambient temperature was not controlled, nor was the subjects' activity restricted.

The purpose of the present study was to examine the effect of cool $\left(19^{\circ} \mathrm{C}\right)$ and warm $\left(31^{\circ} \mathrm{C}\right) T_{\mathrm{a}} \mathrm{s}$ on the frequency, intensity and duration of hot flashes. $A$ preliminary report of this study was presented as a poster paper (Kronenberg and Barnard, 1990).

\section{METHODS}

\section{Subjects}

Six women (5 post-menopausal, 1 perimenopausal) experiencing frequent ( $\geqslant 10 /$ day) hot flashes participated in the study. Each volunteer was interviewed by one of the investigators and completed a questionnaire that included a prospective diary of the times and intensities of all hot flashes experienced for a 2-day period. Prior to acceptance into the study, a health history was taken and individuals with reported medical or psychiatric disorders were excluded. Subjects were healthy, with a mean age of $54.5 \pm 5.6 \mathrm{y}$, and had been having hot flashes for 1-20 y (Table 1). None of the subjects had received hormone therapy for at least 4 months, nor were they currently taking any medication known to affect hot flashes. The procedures were explained, and written informed consent was obtained in accordance with 
Table 1. Subject profile

\begin{tabular}{ccccccccc}
\hline & $\begin{array}{c}\text { Age at } \\
\text { time of } \\
\text { study } \\
(\mathrm{yr})\end{array}$ & $\begin{array}{c}\text { Age at } \\
\text { menopause } \\
(\mathrm{yr})\end{array}$ & $\begin{array}{c}\text { Years } \\
\text { post- } \\
\text { menopause }\end{array}$ & $\begin{array}{c}\text { Type of } \\
\text { menopause }\end{array}$ & $\begin{array}{c}\text { No. of } \\
\text { years } \\
\text { of hot } \\
\text { flashes }\end{array}$ & $\begin{array}{c}\text { Menstrual } \\
\text { cycles } \\
\text { when hot } \\
\text { flashes } \\
\text { started }\end{array}$ & $\begin{array}{c}\text { Height } \\
(\mathrm{cm})\end{array}$ & $\begin{array}{c}\text { Weight } \\
(\mathrm{kg})\end{array}$ \\
\hline 13 & 50 & 36 & 14 & Surgical & 14 & None & 160 & 58.4 \\
54 & 53 & 46 & 7 & Natural & 12 & Regular & 178 & 108.7 \\
62 & 62 & 42 & 20 & Natural & 20 & Regular & 159 & 79.3 \\
78 & 61 & 51 & 10 & Natural & 10 & None & 165 & 05.7 \\
84 & 49 & - & 0 & Perimeno & 1 & Irregular & 163 & 54.4 \\
96 & 52 & 44 & 8 & Surgical & 8 & None & 158 & 80.6 \\
\hline
\end{tabular}

the requirements of the Columbia University Health Sciences Institutional Review Board for Human Investigation Projects.

\section{Measurements}

Studies were conducted in a $15 \mathrm{ft} \times 25 \mathrm{ft}$ temperature-controlled $\left( \pm 1^{\circ} \mathrm{C}\right)$ room (HotPack Corp.), equilibrated to the appropriate ambient temperature. All physiological variables were recorded at 30 -s intervals using either a Squirrel Physiological Data Logger (Science Electronics, Dayton, $\mathrm{OH}$ ) or a Vitalog Physiological Monitor (Clinical Monitoring, Redwood City, CA). The Squirrel and the Vitalog are portable microprocessor data loggers with computer interfaces. The Squirrel was used for 9 experiments and the Vitalog for 3 (subject No. 96 warm \& cool, subject No. $78 \mathrm{cool}$ ), when the Squirrel was inoperative. For 5 of the subjects, the same instrument was used in both their warm and cool sessions. For the sixth subject (subject No. 78), the Squirrel was used in the warm session and the Vitalog in the cool session. Because the Squirrel and Vitalog use slightly different algorithms in their calculation of heart rate, the sixth subject's heart rate data were not included in the analysis. Temperature measurements between the Squirrel and Vitalog are highly correlated, with small mean differences between them ( $T_{\text {core }}$ : $r=0.989, \mu_{\mathrm{D}}=0.145 ; T_{\text {finger }}: r=0.981, \mu_{\mathrm{D}}=0.096$; $T_{\text {chest }}: r=0.777, \mu_{\mathrm{D}}=0.084 ; N=826$ ). Ambient humidity was measured using a hygrothermograph (Serdex).

Heart rate was measured using standard single-use EKG electrodes.

Skin temperatures were measured at two locations (chest, and dorsal surface of the middle phalanx of the index finger of the non-dominant hand) using disc thermistors (YSI, Models 421 \& 409A) attached to the skin with tape and collodion. Chest and finger were chosen because these sites undergo significant temperature changes during a hot flash. There is considerable sweating on the chest during a hot flash. Typically, a decline in chest temperature occurs due to evaporative cooling, particularly in a warm environment. More distal sites tend to exhibit greater increases in skin temperature during hot flashes. Thus, finger temperature provides a good marker of hot flash occurrence, particularly in a cool environment.

Internal body (core) temperature was measured vaginally using a flexible vinyl-covered disposable thermistor (YSI Model 491A) taped to a tampon.

Ambient temperature was measured using a thermistor (YSI Model 421) positioned in the air within $1 \mathrm{~m}$ of the subject's head.
Skin resistance, used as an index of local sweating activity, was recorded using silver silver-chloride electrodes (SensorMedics) placed approximately $2 \mathrm{~cm}$ apart on the chest over the upper sternum.

Subjects were instructed to rate the peak intensity of their hot flashes on a scale of $1-10$, with 1 being the mildest hot flash, and 10 being the most intense hot flash they had ever experienced. They recorded the perceived peak hot flash intensity as well as the beginning and ending times of each hot flash (duration) on a $\log$ sheet.

\section{Procedure}

Each of the six subjects participated in two sessions (warm and cool). The two sessions were conducted within 2 weeks of each other, between November and March, with the exception of one subject (No. 78) for whom the warm session was in August and the cool session was in October. The time of day was the same for all 12 sessions. The subjects reported to the laboratory between $08: 00$ and $09: 00 \mathrm{~h}$ and immediately entered the environmental room which had been equilibrated to either 19 or $31^{\circ} \mathrm{C}$. Order of presentation of $T_{\mathrm{a}}$ was balanced. Clothing was comparable between subjects at each $T_{\mathrm{a}}$. They wore slacks and a short sleeved shirt in the warm $T_{\mathrm{a}}$, and an additional shirt in the cool $T_{\mathrm{a}}$. They sat in a comfortable chair, leaving the environmental room only to use the bathroom. Subjects were instructed to refrain from drinking caffeinated beverages on the morning of the study. The vaginal thermistor was inserted by the subject, and the investigators attached the remaining lead wires, during which time the subject also was equilibrating to the room temperature. Recording commenced between $09: 00$ and 10:00 $\mathrm{h}$ and continued for $8 \mathrm{~h}$. Meals and non-caffeinated beverages were served to the subject in the environmental room. The types and times of all activities were recorded by the subject on the log sheet. On one of the two study days, a venous blood sample was drawn for determination of serum levels of estrone, estradiol, luteinizing hormone (LH) and follicle stimulating hormone (FSH) to confirm menopausal status.

\section{Analysis}

Number of hot flashes (reported and unreported), mean peak hot flash intensity, and mean hot flash duration were determined for each subject during each 8 -h period. Hot flash duration was calculated as the difference between the subjectively recorded beginning and ending time of each hot flash. A repeated measures analysis of variance (ANOVA) followed by paired $t$ tests were conducted to compare the number of hot flashes at the two $T_{\mathrm{a}} \mathrm{s}$ and a comparable 8-h 
period from the subjects' prospective diary. Mean hot flash intensity, mean hot flash duration, 8-h mean heart rate and 8 -h mean core, skin and chest temperatures were also compared using paired $t$ tests.

Hot flashes are marked by specific physiological changes, the patterns and time courses of which have been well-characterized (Kronenberg et al., 1984; Tataryn et al., 1980). The physiological criterion for a hot flash was the concurrent occurrence (within $3 \mathrm{~min}$ ) of an appropriate change in two of the recorded variables (i.e. increase in finger temperature, increase in heart rate, decrease in skin resistance, core or chest temperature). Hot flashes that were not reported by the subject, but were identified by this criterion were labelled "unreported hot flashes." Hormone analysis confirmed the subjects' reported menopausal status. For the 5 menopausal women, serum estradiol was $<20 \mathrm{pg} / \mathrm{ml}$ and $\mathrm{FSH}$ was $>50 \mathrm{mIU} / \mathrm{ml}$. The perimenopausal women had a serum estradiol level of $80 \mathrm{pg} / \mathrm{ml}$ and an FSH level of $52 \mathrm{mIU} / \mathrm{ml}$.

\section{RESULTS}

A total of 93 hot flashes were reported in 12 experiments: 75 hot flashes in the warm environment and 18 in the cool environment. Hot flashes were significantly less frequent, less intense and of shorter duration at the cool $T_{\mathrm{a}}$ than at the warm $T_{\mathrm{a}}$ (Fig. 1, Table 2). Evey reported hot flash was associated with corresponding physiological changes. There was one instance of an unreported hot flash at the cool $T_{\mathrm{a}}$ (No. 13) and two unreported hot flashes at the warm $T_{\text {a }}$ (No. 96). The hot flash occurrences with their corresponding subjective intensities at warm and cool $T_{\mathrm{a}} \mathrm{s}$ are shown in Fig. 2. One subject had no hot flashes at the cool $T_{\mathrm{a}}$.

Mean heart rate and mean finger and chest temperatures were significantly higher at the warm than the cool $T_{\mathrm{a}}$. The difference in mean core temperature at warm and cool $T_{\mathrm{a}} \mathrm{s}$ was in the same direction (Table 2).

\section{Effect of Ambient Temperature on Hot Flash Parameters}

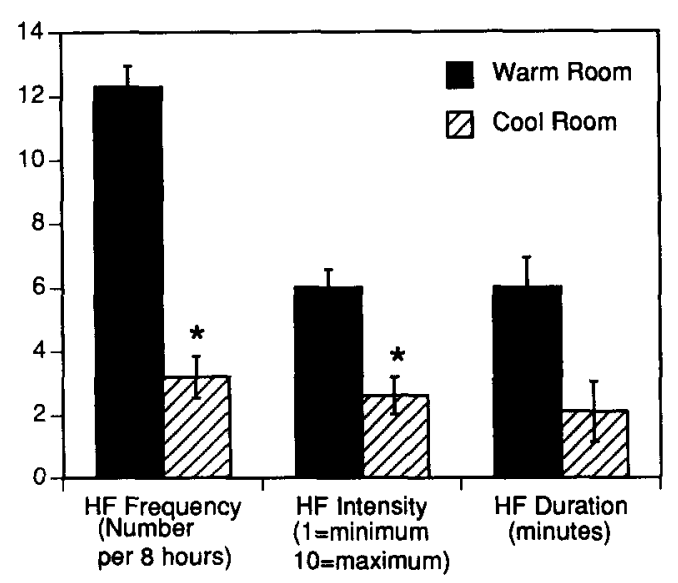

Fig. 1. Mean frequency, intensity and duration of hot flashes at warm vs cool ambient temperatures \pm 1 SEM. ${ }^{*} P<0.05$. The units of the $y$-axis vary with parameter, as indicated.
The physiological measures that best serve as markers of hot flash occurrence differed between the warm and cool $T_{\mathrm{a}} \mathrm{s}$. Skin resistance and finger temperature responses for one subject are presented in Fig. 3 to illustrate the different patterns of physiological responses at the two $T_{\mathrm{a}} \mathrm{s}$. At the cool $T_{\mathrm{a}}$, subjects exhibited cutaneous vasoconstriction and reported feeling chilly. In this environment, an increase in finger temperature and decrease in skin resistance were the best indicators of hot flashes [as exemplified in Fig. 3(B)]. The skin resistance response during a hot flash at cool $T_{\mathrm{a}}$ has a very characteristic rate of change and time course. At the warm $T_{\mathrm{a}}$, subjects exhibited cutaneous vasodilation, and intermittent sweating as indicated by lower, fluctuating skin resistance values [exemplified in Fig. 3(A)]. A hot flash-associated decrease in skin resistance was more difficult to differentiate clearly from ongoing sweating at the warm $T_{\mathrm{a}}$. The best indicators of a hot flash in the warm environment tended to be an increase in heart rate and a decrease in chest temperature (due to sweating and evaporative cooling) [Fig. 4(A)]. There was little finger temperature response during a hot flash at the warm $T_{\mathrm{a}}$ since the skin tended to be already vasodilated.

Data from the prospective diaries were examined (Table 3). Five of the subjects' records were completed 2 days to 4 months prior to the laboratory experiments; the sixth subject's diary was recorded 1 year earlier. (This subject [No. 62] has participated in the first author's studies for 8 years, during which time the pattern of her hot flashes has continued, essentially unchanged.) The number of hot flashes for a corresponding 8 -h period in the prospective diary was compared with the number of hot flashes during the warm and cool $T_{\mathrm{a}}$ experiments. A repeated measures ANOVA showed statistically significant differences among the three groups $(F=21.88$, $P<0.005$, d.f. $=2,10$ ). Paired $t$-tests were used for post hoc comparisons. For all subjects, the number of hot flashes outside the laboratory (prospective diary) fell between and was significantly different from the numbers reported at both the warm $(t=3.45$, $P \leqslant 0.018$, d.f. $=5)$ and $\operatorname{cool}(t=-2.77, P \leqslant 0.04$, $\mathrm{df}=5$ ) experimental $T_{\mathrm{a}} \mathrm{s}$. Four subjects recorded hot flash intensity in the prospective diary. Paired $t$-tests were used to compare laboratory with diary hot flash intensity ratings. The mean diary intensity fell between and was significantly different from the intensity values at the two laboratory $T_{\mathrm{a}} \mathrm{s}$ (cool $T_{\mathrm{a}}$, $P \leqslant 0.028$; warm $T_{\mathrm{a}}, P \leqslant 0.026$ ). The ambient temperature in the non-laboratory setting was not recorded, but most likely fell between the two experimental $T_{\mathrm{a}} \mathrm{s}$.

\section{DISCUSSION}

There were significantly fewer, less intense hot flashes at the cool $T_{\mathrm{a}}$ than at the warm $T_{\mathrm{a}}$, and these hot flashes tended to be shorter in duration. One subject experienced no hot flashes at all in the cool room. At this air temperature, she had the lowest mean finger and core temperatures of all subjects; she was also the thinnest subject (No. 84). At an even cooler $T_{\mathrm{a}}$, perhaps the hot flashes of other subjects also would have been completely suppressed. 
Table 2. Comparison of selected measures at warm and cool ambient temperatures

\begin{tabular}{lcccrc}
\hline Measure & $N$ & $\begin{array}{c}T_{\mathrm{a}}=31^{\circ} \mathrm{C} \\
\text { Mean } \pm \mathrm{SD}\end{array}$ & $\begin{array}{c}T_{\mathrm{a}}=19^{\circ} \mathrm{C} \\
\text { Mean } \pm \mathrm{SD}\end{array}$ & Paired $t$ & $P$ \\
\hline Hot flashes/8 $\mathrm{h}^{*}$ & 6 & $12.3 \pm 1.6$ & $3.2 \pm 2.5$ & 11.692 & 0.000 \\
Peak hot flash intensity & $5 \dagger$ & $6.0 \pm 1.4$ & $2.6 \pm 0.8$ & 5.061 & 0.007 \\
Hot flash duration (min) & $4+\ddagger$ & $6.0 \pm 2.3$ & $2.1 \pm 0.4$ & 3.089 & 0.054 \\
Mean heart rate (bpm) & $5 \S$ & $86.2 \pm 9.9$ & $73.8 \pm 10.4$ & 8.078 & 0.001 \\
Mean core temperature (C) & 6 & $37.2 \pm 0.2$ & $36.9 \pm 0.2$ & 2.498 & 0.055 \\
Mean finger temperature (C) & 54 & $35.6 \pm 0.2$ & $22.0 \pm 1.6$ & 19.968 & 0.000 \\
Mean chest temperature (C) & 34 & $35.5 \pm 0.2$ & $35.2 \pm 0.7$ & 9.634 & 0.011 \\
\hline
\end{tabular}

*Includes reported and unreported hot flashes.

tOne subject did not have any hot flashes in the cool room, and her data could not be included for intensity and duration comparisons.

†One subject did not record hot flash ending times so duration could not be calculated.

\$One subject eliminated due to different method of heart rate data collection.

Some subjects eliminated because of missing data due to data logger problem.

Further suggestion of a modulating effect of ambient temperature on hot flashes is provided by a comparison of the number and intensity of hot flashes experienced in the laboratory, with the number and intensity of hot flashes experienced by the subjects in their typical surroundings (prospective diary). It is likely that the ambient temperature in these surroundings was between the warm and cool laboratory temperatures, since the laboratory temperatures were somewhat above and below typical home temperatures. Both the frequencies and the intensities of the hot flashes reported in the prospective diaries fell between the laboratory values. This suggests that not only does cool temperature lessen hot flashes, but also that warm temperature exacerbates hot flashes. While activity levels during the two experimental conditions were similar, the subjects' activities during the period of the prospective diary recording is unknown. At present, there are no experimental data assessing the relationship between hot flash occurrence and activity.

Anecdotally, some women report that particular events trigger hot flashes (Kronenberg, 1990).
Although there are no other studies of the effect of controlled $T_{\mathrm{a}}$ on hot flashes, direct heating of the torso has been used to provoke hot flashes (Sturdee et al., 1978; Freedman, 1989). While data from the present study indicate that cool $T_{\mathrm{a}}$ reduces hot flashes, similar results might be obtained by providing a cool stimulus to a more restricted area of skin, particularly one with relatively high thermal sensitivity, such as the face (Crawshaw et al., 1975).

We expected that women would report fewer hot flashes at the $\operatorname{cool} T_{\mathrm{a}}$; however, the question remained whether this reduction in reported hot flash frequency would be evidenced physiologically. At the cool $T_{\mathrm{a}}$, all subjects exhibited fewer hot flashes, both subjectively and objectively. In contrast to these results, investigators who administered clonidine to women with hot flashes reported a dissociation of the perception of a hot flash from the concomitant physiological changes (Tulandi et al., 1983). After clonidine administration, the skin temperature increases characteristic of hot flashes continued with no changes in frequency; however, 7 out of 8 women reported fewer or no hot flashes. The reported hot flashes were less
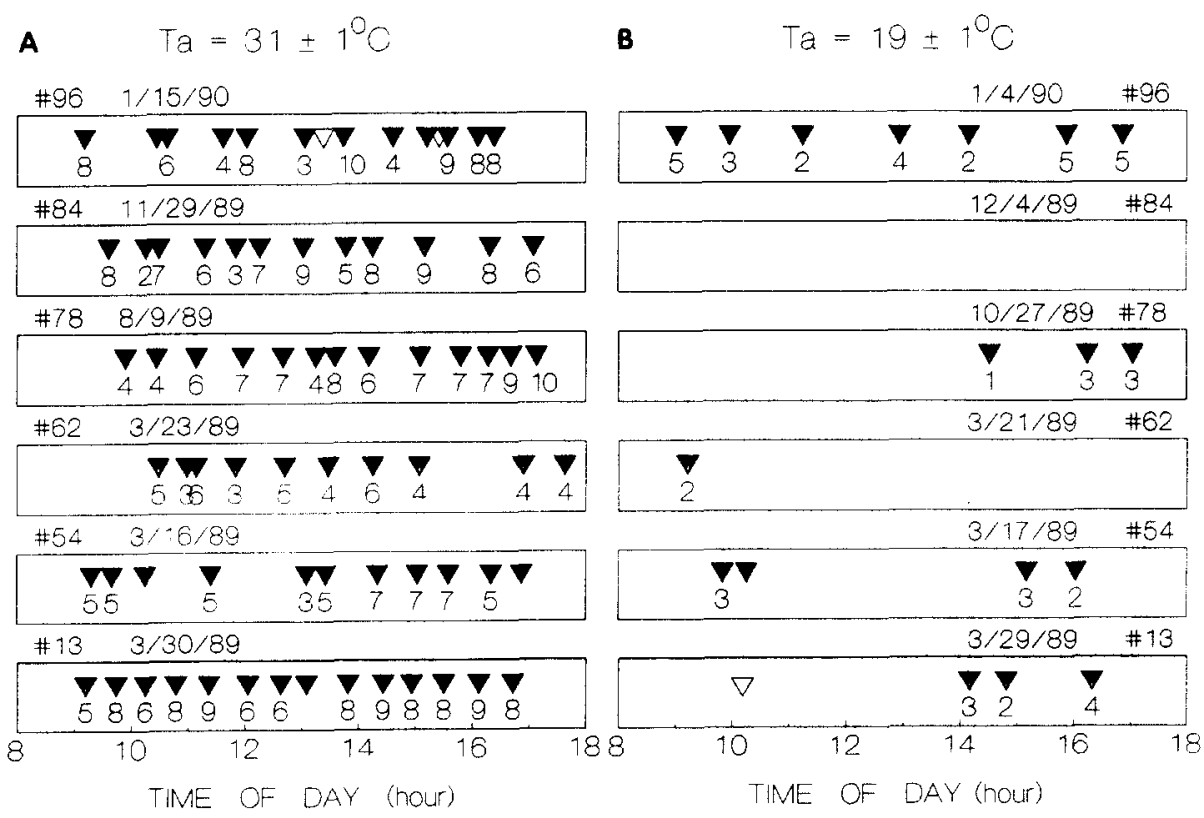

Fig. 2. Hot flash occurrence and intensity at $31^{\circ} \mathrm{C}$ and $19^{\circ} \mathrm{C}$ for 6 subjects. $\nabla$, indicates reported hot flash; $\nabla$, indicates unreported hot flash. Intensity is rounded to the nearest whole number when a subject reported the rating as a decimal. Some hot flashes were not rated. 

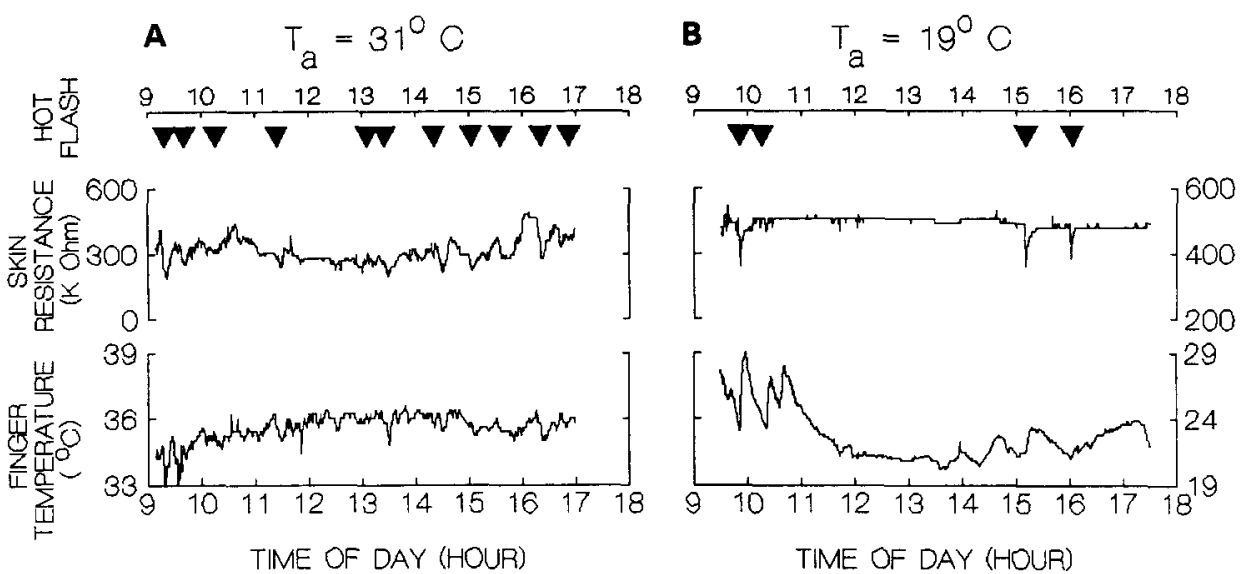

Fig. 3. Skin resistance and skin (finger) temperature responses during $8 \mathrm{~h}$ at (A) $31^{\circ} \mathrm{C}$ and (B) $19^{\circ} \mathrm{C}$ for one subject (No. 54). $\boldsymbol{\nabla}$, reported hot flash.

intense after clonidine. There may be a continuum of hot flashes, ranging from those of sufficient magnitude physiologically to be perceived to others which can be detected physiologically but which fall below the threshold of perception. Clonidine may block a perceptual pathway, leaving other responses intact.

The perceived intensity of a hot flash may be the result of a combination of factors. Studies of thermal comfort suggest that various thermal factors contribute to temperature sensation. Air, skin and internal body temperatures play a role in temperature sensation (hot/cold) and thermal comfort (pleasant/unpleasant) ratings (Attia, 1984). When a hot peripheral thermal stimulus is administered to a hypothermic individual, she may report that it feels hot, but that it feels good (Cabanac et al., 1976). One can thus be hot (or cold) and comfortable or hot (or cold) and uncomfortable, depending on a combination of internal and external parameters (Cabanac et al., 1971; Gagge et al., 1967; Cabanac et al., 1976). A hot flash in a cool $T_{\mathrm{a}}$ may temporarily reduce the subjective discomfort of the cool room due to rapid warming of the skin. The cool environment also may reduce the discomfort of the hot flash by facilitating heat loss; the hot flash might thereby be perceived as less intense than a hot flash in a warm $T_{\mathrm{a}}$. At a warm $T_{\mathrm{a}}$, the vasodilation and sweating during a hot flash may increase the subjective discomfort that already exists in the warm room, and thus, increase the perceived intensity of the hot flash.

In addition to ambient temperature, circadian factors may influence perceived intensity of hot flashes. There is one report of a diurnal rhythm of hot flash intensity, with a nadir at about midday (Kronenberg and Downey, 1988). During each of our 8-h sessions at constant $T_{\mathrm{a}}$, subjects experienced hot flashes of varying intensities. In this short period of time, we did not discern a clear temporal pattern of hot flash intensity, however, the lowest intensity rating tended to occur between 11:00 and 14:00 h.

Several possible mechanisms could explain the influence of ambient temperature on hot flash occurrence and/or intensity. The number and intensity of hot flashes in a particular temperature environment
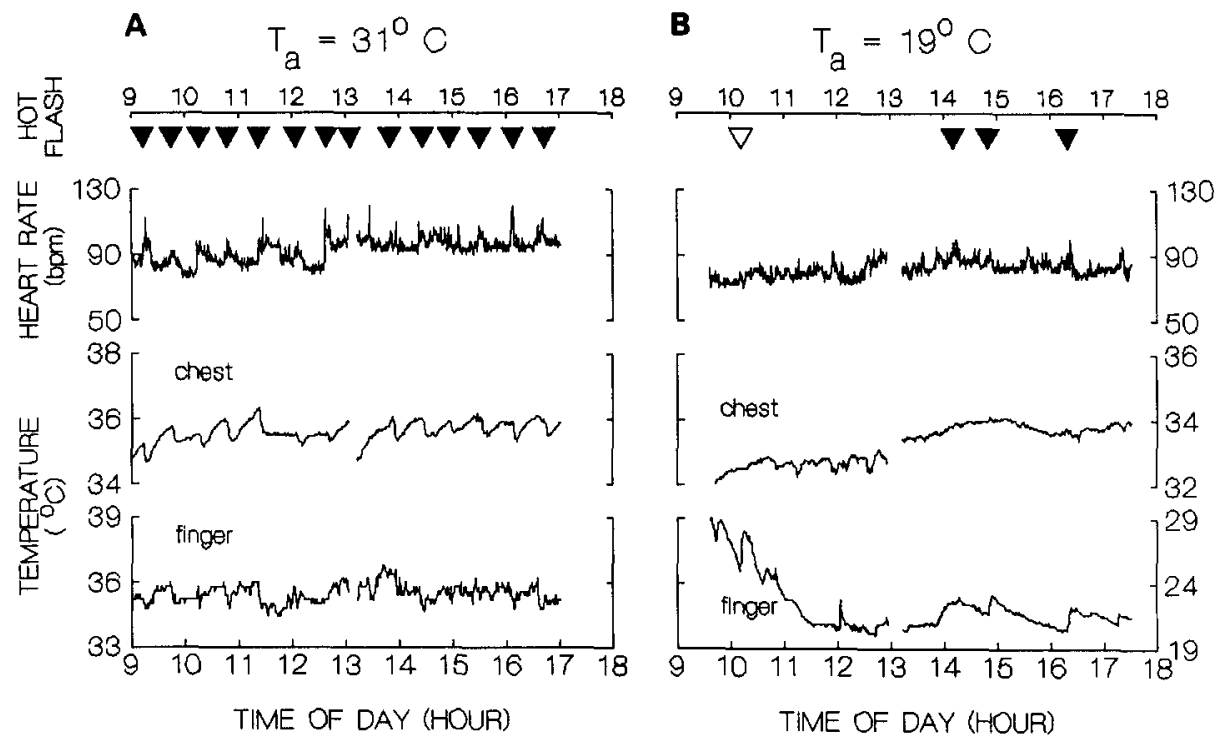

Fig. 4. Heart rate and skin (chest and finger) temperatures during $8 \mathrm{~h}$ at (A) $31^{\circ} \mathrm{C}$ and (B) $19^{\circ} \mathrm{C}$ for one subject (No. 13). $\nabla$, reported hot flash; $\nabla$, unreported hot flashes. 
Table 3. Comparison of reported number and mean intensity of hot fiashes for 8 -h periods under three ambient conditions

\begin{tabular}{|c|c|c|c|c|c|c|c|c|c|}
\hline \multirow[b]{2}{*}{ ID No. } & \multicolumn{3}{|c|}{ Number of hot flashes } & \multicolumn{3}{|c|}{ Data collection dates } & \multicolumn{3}{|c|}{ Hot flash intensity } \\
\hline & Warm $T_{\mathrm{d}}^{*}$ & Diary ${ }^{\dagger}$ & $\operatorname{Cool} T_{\mathrm{i}}^{*}$ & Warm & Diary & Cool & Warm $T_{\mathrm{a}+}^{+}$ & Diary ${ }^{+}$ & $\operatorname{Cool} T_{i+}^{+}$ \\
\hline 13 & 14 & 11 & 3 & $03 / 30 / 90$ & $11 / 19 / 89$ & $03 / 29 / 90$ & 7.5 & NA & 30 \\
\hline 54 & $1 !$ & 7 & 4 & $03 / 16 / 90$ & $03 / 14 / 90$ & $03 / 17 / 90$ & 5.4 & NA & 2.7 \\
\hline 62 & 10 & 8 & 1 & $03 / 23 / 90$ & $01 / 15 / 88$ & $03 / 21 / 90$ & 3.9 & 3.4 & 1.5 \\
\hline 78 & 1.3 & 13 & 3 & $08 / 09 / 89$ & $06 / 10 / 89$ & $10 / 27 / 89$ & 6.6 & 5.7 & 23 \\
\hline 84 & 12 & 2 & 0 & $11 / 29 / 89$ & $07 / 25 / 89$ & $12 / 04 / 89$ & 6.5 & 40 & . \\
\hline 96 & 12 & 8 & 7 & $01 / 15 / 90$ & $12 / 07 / 89$ & $01 / 04 / 90$ & 6.8 & 6.0 & 36 \\
\hline
\end{tabular}

Warm $T=31 \mathrm{C}:$ cool $T=19 \mathrm{C}$

* Self-reported in laboratory and confirmed by physiological monitoring.

tSelf-reported: 8 daytime hours from the prospective diary

${ }_{+}^{+}$Selli-reported in laboratory.

$\mathrm{NA}=$ not available

might be determined by competing thermal drives. In a cool environment, for example, these would be a drive for heat conservation due to the cool ambient temperature, and a drive for heat loss due to the occurrence of a hot flash. The relative strengths of these two drives might determine whether or not a hot flash is expressed. either physiologically or perceptually, in a cold room. A hot flash might be triggered, but the resultant drive for heat loss might not be as strong as the drive to conserve heat in a cold environment, thereby essentially inhibiting the hot flashes. With just one exception, all hot flashes that occurred in the cool room (as determined physiologically) were perceived by the subjects. It is, therefore, unlikely that the cold temperature used in this study masks the perception of a hot flash while leaving physiological changes intact. This is contrary to what occurred with the administration of clonidine mentioned above. In a warm $T_{\mathrm{a}}$ there are two drives for heat loss (warm $T_{\mathrm{a}}$, and occurrence of a hot flash), which may be additive. producing an even stronger drive for heat loss and the sensation of a more intense hot flash, as was observed in this study. Obtaining a detailed heat balance profile would help us to clarify these issues.

A second (and not mutually exclusive) mechanism by which $T_{\mathrm{a}}$ might act is through an effect on thresholds for thermoregulatory effector responses. Ambient temperature influences central temperature thresholds for thermoregulatory effector processes such as shivering and sweating (Benzinger, 1969; Hammel, 1968; Boulant and Gonzalez, 1977). Similarly, a sufficiently prolonged external thermal stress might shift thermoregulatory set points for the effector responses involved in a hot flash. In the heat, for example, if the thresholds for heat loss responses were lowered, hot flashes might be more easily triggered. Conversely, in a cold environment, if thermoregulatory thresholds were raised, hot flashes might be more difficult to trigger. These possibilities could be assessed through an examination of the core and skin temperatures at which vasodilation and sweating occurred in the two $T_{\mathrm{i}} \mathrm{s}$.

There also may be a direct effect of ambient temperature on the thermoregulatory effectors involved in hot flashes. Ambient temperature is known to change activities of certain thermoregulatory effectors through a direct action on skin and local tissue temperature. For example, sweat gland activity is influenced by local skin temperature (Bullard et al., 1970). During a hot flash, sweating and vasodilation might be modulated by ambient temperature effects on the sweat glands or blood vessels themselves Localized application of heat to the torso has been reported to provoke a hot flash in symptomatic women. However, hot flash patterns prior to this heat application were not presented, making it difficult to determine whether a hot flash was triggered before it would have otherwise occurred (Sturdee et al., 1978; Freedman, 1989).

A fourth possibility is that ambient temperature might influence the mechanism that initiates a hot flash. Whether this mechanism is a neuronal pacemaker, or the release of some hot flash triggering substance, it might be inhibited or stimulated by the direct or indirect effects of ambient temperature on the body.

Clearly, estrogen plays a role in the hot flash phenomenon, since hot flashes can occur immediately upon withdrawal of estrogen (e.g. bilateral ovariectomy), and they can be suppressed by the administration of estrogen. But neither the site of action nor mechanism by which estrogen exerts its effects is known. An interaction between female reproductive hormones and the thermoregulatory system is presumed to underlie the body temperature rhythm during the menstrual cycle, and differences in thermoregulatory effector responses between the luteal and follicular phases of the menstrual cycle (Kenshalo, 1966; Hessemer and Bruck, 1985 Stephenson and Kolka, 1985). However, the mechanisms through which estrogen or progesterone act to affect thermoregulatory function have not been established. Hot flashes provide another example through which to examine the interplay between reproductive hormones and thermoregulation.

In summary, although we still do not know what triggers an individual hot flash, environmental temperature has a marked effect on hot flashes, with cool $T_{\text {a }}$ reducing both their frequency and intensity. Cool air temperatures should provide relief to women experiencing frequent, severe hot flashes. Investigators who examine the effectiveness of various interventions on hot flashes should report ambient temperature, so the results can be interpreted with respect to possible temperature effects.

Acknowledgements - We would like to thank L. J. Côté. S. Teitelbaum and J. A. Downey for their valuable comments the laboratory of Dr W. Hembree for the hormone analyses and the subjects for contributing their hot flashes. This study was supported by the Vidda Foundation, the Florence 
and Herbert Irving Endowment, NIH 1F33NR06351 and BRSG S07RR-05796, and was conducted while Dr Barnard was on sabbatical leave at Columbia University.

\section{REFERENCES}

Attia M. (1984) Thermal pleasantness and temperature regulation in man. Neurosci. Biobehav. Rev. 8, 335-342.

Benzinger T. H. (1969) Heat regulation: homeostasis of central temperature in man. Physiol. Rev. 49, 671-759.

Boulant J. A. and Gonzalez R. R. (1977) The effect of skin temperature on the hypothalamic control of heat loss and heat production. Brain Res. 140, 367-372.

Bullard R. W., Banerjee M. R., Chen F., Elizondo R. and MacIntyre B. A. (1970) Skin temperature and thermoregulatory sweating: a control systems approach. In Physiological and Behavioral Temperature Regulation (Edited by Hardy J. D., Gagge A. P. and Stolwijk J. A. J.), pp. 597-610. C. C. Thomas, Springfield, IL.

Cabanac M., Cunningham D. J. and Stolwijk J. A. J. (1971) Thermoregulatory set point during exercise: a behavioral approach. J. comp. Physiol. Psychol. 76, 94-102.

Cabanac M., Hildebrandt G., Massonnet B. and Strempel H. (1976) A study of the nycthemeral cycle of behavioural temperature regulation in man. $J$. Physiol. 257, 275-291.

Coope J., Williams S. and Patterson J. S. (1978) A study of the effectiveness of propranolol in menopausal hot flushes. Br. J. Obstet. Gynaecol. 85, 472-475.

Crawshaw L. I., Nadel E. R., Stolwijk J. A. J. and Stamford B. A. (1975) Effect of local cooling on sweating rate and cold sensation. Pflugers Arch. 354, 19-27.

Freedman R. R. (1989) Laboratory and ambulatory monitoring of menopausal hot flashes. Psychophysiology 26, 573-579.

Gagge A. P., Stolwijk J. A. J. and Hardy J. D. (1967) Comfort and thermal sensations and associated physiological responses at various ambient temperatures. Environ. Res. 1, 1-20.

Gannon L., Hansel S. and Goodwin J. (1967) Correlates of menopausal hot flashes. J. behav. Med. 10, 277-285.

Hammel H. T. (1988) Regulation of internal body temperature. Ann. Rev. Physiol. 30, 641-709.

Hessemer V. and Bruck K. (1985) Influence of menstrual cycle on shivering, skin blood flow, and sweating re- sponses measured at night. J. appl. Physiol. 59, 1902-1910.

Kenshalo D. R. (1966) Changes in the cool threshold associated with phases of the menstrual cycle. J. appl. Physiol. Respirat. environ. Exercise Physiol. 21, 1031-1039.

Kronenberg F. (1990) Hot flashes: epidemiology and physiology. Ann. N.Y. Acad. Sci. 592, 52-86.

Kronenberg F. and Barnard R. M. (1990) Influence of ambient temperature on frequency and intensity of menopausal hot flashes. Ann. N.Y. Acad. Sci. 592, 481-485.

Kronenberg F., Cote L. J., Linkie D. M., Dyrenfurth I. and Downey J. A. (1984) Menopausal hot flashes: thermoregulatory, cardiovascular and circulating catecholamine and LH changes. Maturitas 6, 31-43.

Kronenberg F. and Downey J. A. (1988) Diurnal variation of the intensity of menopausal hot flashes. Fed. Proc. 2, A727.

Molnar G. (1981) Menopausal hot flashes: their cycles and relation to air temperature. Obstet. Gynecol. 57, 52S-55S.

Stephenson L. A. and Kolka M. A. (1985) Menstrual cycle phase and time of day after reference signal controlling arm blood flow and sweating. Am. J. Physiol.: Regulatory integrative comp. Physiol. 249, R186-R191.

Sturdee D. W., Wilson K. A., Pipili E. and Crocker A. D. (1978) Physiological aspects of menopausal hot flash. $\mathrm{Br}$. Med. J. 2, 79-80.

Tataryn I. V., Lomax P., Bajorek J. G., Chesarek W., Meldrum D. R. and Judd H. L. (1980) Postmenopausal hot flushes: a disorder of thermoregulation. Maturitas 2, 101-107.

Tataryn I. V., Meldrum D. R., Frumar A. M., Lu K. H., Judd H. L., Bajorek J. G., Chesarek W. and Lomax P. (1980) The hormonal and thermoregulatory changes in postmenopausal hot flushes. In Thermoregulatory Mechanisms and their Therapeutic Implications (Edited by Cox B., Lomax P., Milton A. S. and Schonbaum E.), pp. 202-207. S. Karger, Basel.

Tulandi T., Lal S. and Kinch R. A. (1983) Effect of intravenous clonidine on menopausal flushing and luteinizing hormone secretion. Br. J. Obstet. Gynecol. 90, 854857.

Voda A. M. (1981) Climacteric hot flash. Maturitas 3, 73-90. 